\section{Arrivoc

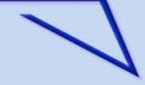

Archive for

Organic Chemistry
The Free Internet Journal

for Organic Chemistry
Paper

Arkivoc 2017, part v, 216-228

\title{
Vapor phase phototransposition chemistry of dimethylpyrazines and dimethylpyrimidines
}

\author{
James W. Pavlik, ${ }^{a *}$ Tharinee Vongakorn, ${ }^{a}$ and Naod Kebede ${ }^{b}$ \\ ${ }^{a}$ Department of Chemistry and Biochemistry, Worcester Polytechnic Institute, \\ Worcester, Massachusetts 01609, USA \\ ${ }^{b}$ Department of Chemistry, Edinboro University, Edinboro, Pennsylvania 16444, USA \\ E-mail:jwpavlik@wpi.edu
}

This paper is dedicated to Dr. Robert E. Connors (October 1, 1945 - July 16, 2015), friend and colleague, in recognition of his many contributions to spectroscopy and photochemistry

Received 07-18-2017

Accepted 09-23-2017

Published on line $10-26-2017$

\section{Abstract}

Based on their phototransposition chemistry, the three dimethylpyrazines and four dimethylpyrimidines can be arranged into two groups. 2,5-Dimethylpyrazine, 2,5-dimethylpyrimidine, and 4,6-dimethylpyrimidine constitute a photochemical triad. Irradiation of any one member of the triad in the vapor phase results in the formation of the other two members. The other four isomers, 2,6-dimethylpyrazine, 2,3-dimethylpyrazine, 2,4dimethylpyrimidine, and 4,5-dimethylpyrimidine constitute a photochemical tetrad. Irradiation of any one member results in the formation of the other three. In addition, 2,4-dimethylpyrimidine and 2,6-dimethylpyrazine also photoisomerize to 3,6-dimethylpyridazine. Irradiation of the last in the vapor state resulted in the four members of the tetrad.
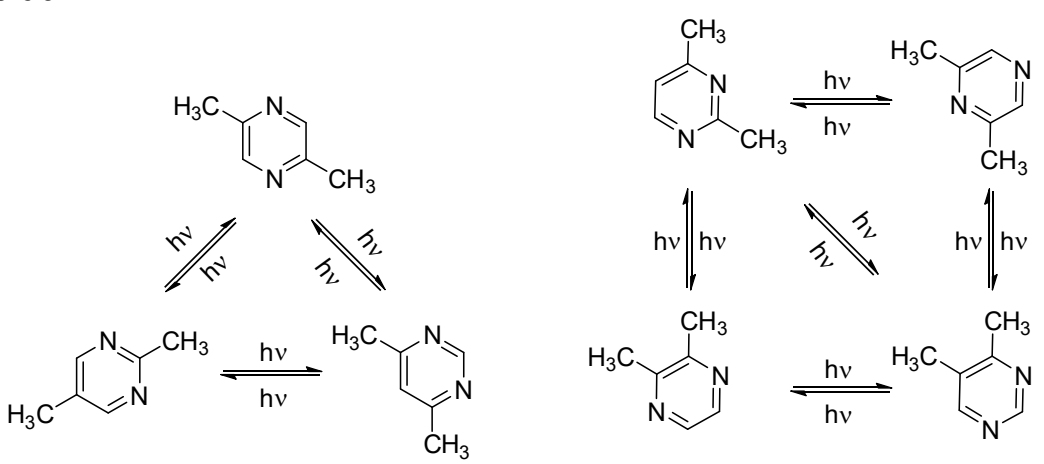

Keywords: Dimethylpyrazines, dimethylpyrimidines, vapor phase, phototransposition, photoisomerization 


\section{Introduction}

Lahmani and coworkers reported over 40 years ago that pyrazine 1 undergoes vapor phase phototransposition to pyrimidine $2 .^{1-3}$ These same workers reported that methylpyrazine $\mathbf{3}$ and dimethylpyrazines $\mathbf{4}$ and $\mathbf{5}$ undergo vapor phase photoisomerization to yield pyrimidines 6-12 (Figure 1).

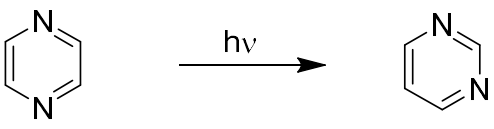

1

2

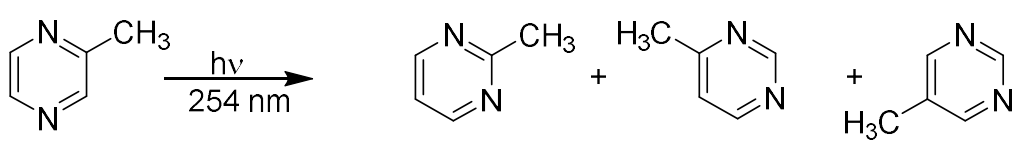

3

6

7

8

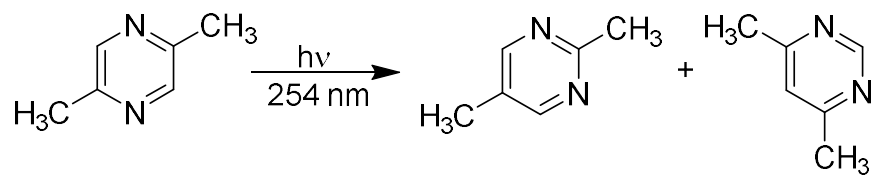

4

9

10

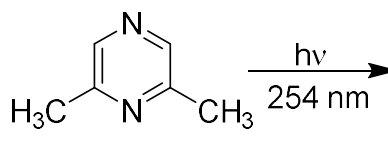

5<smiles>Cc1cncnc1C</smiles>

11<smiles>Cc1ccnc(C)n1</smiles>

12

Figure 1. Previously observed products from vapor phase phototranspositions of pyrazines 1, 3-5.

According to these workers, these photoisomerizations are 100 times more efficient upon direct $\pi \rightarrow \pi^{*}$ excitation than upon direct $\mathrm{n} \rightarrow \pi^{*}$ excitation. Based on these few examples, it was concluded that "a compound of benzvalene type structure is the most probable intermediate in these transformations."

More recently, we used deuterium labeling to study the vapor phase phototransposition chemistry of pyrazine $1 .{ }^{4} \mathrm{GLC}$ and ${ }^{1} \mathrm{H}$ NMR analyses of the product mixtures revealed that 2,5-dideuteriopyrazine $1-2,5-d_{2}$ and 2,6-dideuteriopyrazine 1-2,6- $d_{2}$ each transposed to a mixture of two isomeric dideuteriopyrimidines and a trace quantity of a dideuteriopyridazine (Figure 2). Although these transpositions cannot be explained by a mechanistic path involving Dewar-diazaprismane intermediates, they are identical to those predicted by a diazaprefulvene mechanism. A similar biradical structure, called prefulvene, was first suggested by Bryce-Smith and Longuet-Higgins to be an intermediate in the photoisomerization of benzene. ${ }^{5}$ 
<smiles>[2H]c1cnc([2H])cn1</smiles>

$1-2,5-d_{2}$<smiles>[2H]c1cncc([2H])n1</smiles>

$1-2,6-d_{2}$<smiles>[2H]c1cnc([2H])nc1</smiles><smiles>[2H]c1cc([2H])ncn1</smiles>

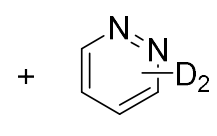

$2-2,6-d_{2}$

$2-4,6-d_{2}$

$13-d_{2}$<smiles>[2H]c1cncnc1[2H]</smiles>

$2-4,6-d_{2}$

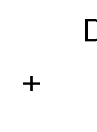<smiles>[2H]c1ccnc([2H])n1</smiles>

$2-2,4-d_{2}$ $13-d_{2}$<smiles>[R6]c1ncccn1</smiles>

Figure 2. Vapor phase phototransposition studies of deuterium labeled pyrazine 1.

Although the photoreactions of the dimethylpyrazines (Figure 1) have been known for over four decades, no complete mechanistic scheme for the vapor phase phototransposition chemistry of dimethylpyrazines and dimethylpyrimidines has appeared in the literature. To better understand the photochemistry of these compounds we studied the vapor phase photochemistry of a complete set of dimethylpyrazines and dimethylpyrimidines. These include the three possible dimethylpyrazines (4, 5 and 14) and the four possible dimethylpyrimidines $\mathbf{9 - 1 2}$ as well as a dimethylpyridazine 15 (Figure 3).<smiles>Cc1cnc(C)cn1</smiles><smiles>Cc1cncc(C)n1</smiles>

4<smiles>Cc1cc(C)ncn1</smiles>

10<smiles>Cc1cncnc1C</smiles>

11<smiles>Cc1nccnc1C</smiles>

14<smiles>Cc1ccnc(C)n1</smiles>

12<smiles>Cc1cnc(C)nc1</smiles>

9

Figure 3. Dimethyl-substituted diazines studied herein.

\section{Results and Discussion}

Each dimethylpyrazine (4, 5 or 14) and dimethylpyrimidine (9-12) vapor, with a total pressure of 1.0-1.5 Torr, was irradiated for 5 minutes in a three-liter quartz vessel in a Rayonet reactor with light of $254 \mathrm{~nm}$ emitted from 2, 4, 6, or 8 low pressure $\mathrm{Hg}$ lamps. After each irradiation, the volatile materials were pumped out of the reaction flask, condensed and dissolved either in a standard volume of ether for quantitative GLC analysis or in deuteriochloroform for ${ }^{1} \mathrm{H}$ NMR analysis. Products were identified by GLC retention times, by GLC co-injections with authentic samples, and by comparison of the observed ${ }^{1} \mathrm{H}$ NMR chemical shifts with the chemical shifts of authentic samples of the various isomeric products. 
<smiles>Cc1ccc(C)nn1</smiles>
14
5
12
$(-47 \%)$
$(0.8 \%)$
$(5.7 \%)$
$(5.7 \%)$
15
(trace)

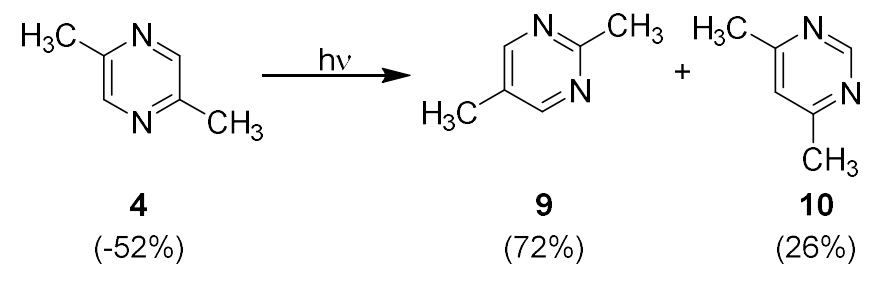<smiles>Cc1ccc(C)nn1</smiles><smiles></smiles><smiles>CCCCCCc1cc(C)ncc1C</smiles>

$(-45 \%) \quad(62 \%)$

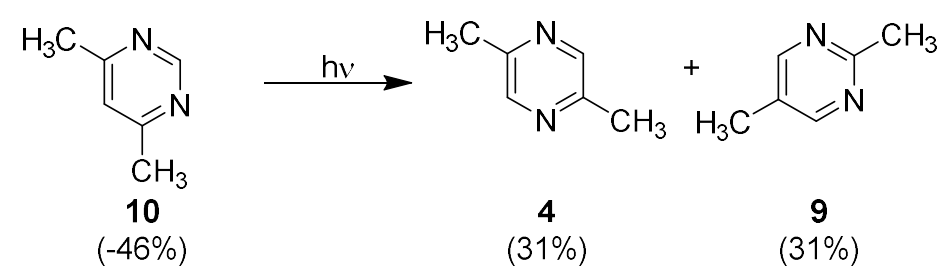<smiles>Cc1ccnc(C)n1</smiles>

Figure 4. Primary products; positive numbers give products yields, negative numbers give consumption yields.

The photoreactions were studied under a wide range of reactant conversions to differentiate primary and secondary products. Figure 4 shows the maximum quantity of primary photoproducts formed from each dimethyldiazine. Inspection of these products revealed that the seven dimethyldiazines can be arranged into two distinct groups: The first group contains 2,5-dimethylpyrazine 4, 2,5-dimethylpyrimidine 9, and 4,5dimethylpyrimidine 10, and constitutes a photochemical triad (Scheme 1); irradiation of any member of the triad results in the formation of the other two members as the only isomerization products. The second group 
contains the other four isomers, 2,6-dimethylpyrazine 5, 2,3-dimethylpyrazine 14, 2,4-dimethylpyrimidine 12 and 4,5-dimethylpyrimidine 11, and constitutes a photochemical tetrad (Scheme 2).

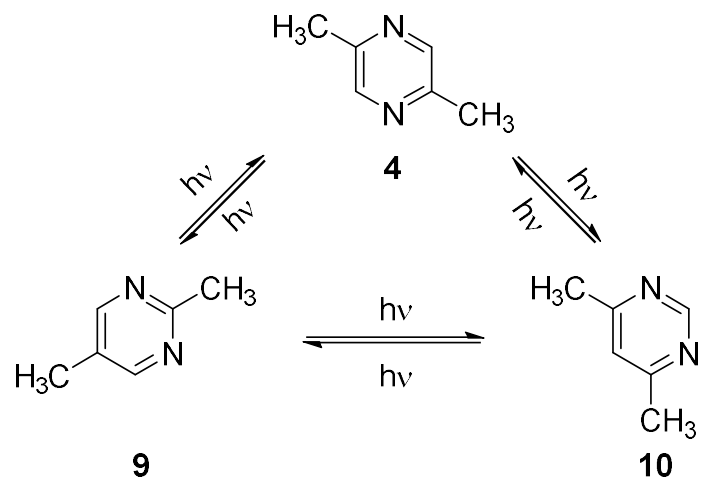

Scheme 1. Photointerconversions within triad.

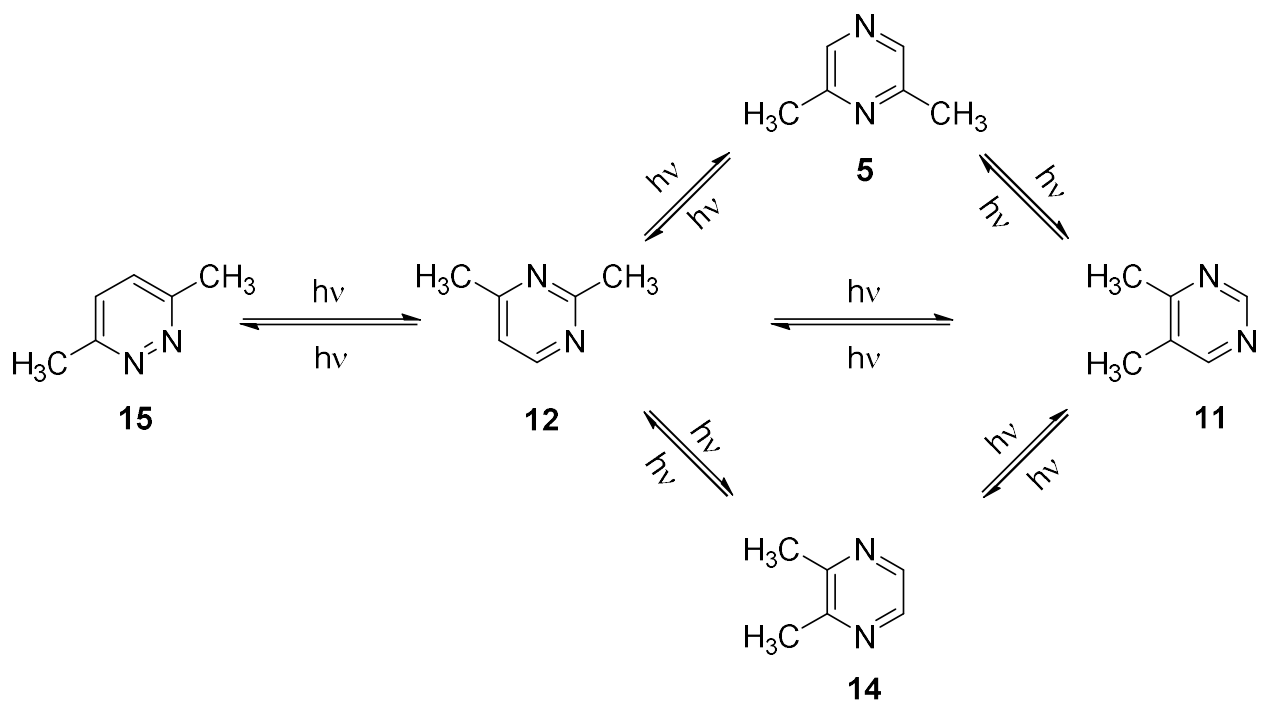

Scheme 2. Photointerconversions within tetrad.

Irradiation of any member of the tetrad led to the formation of the other three. In addition to phototransposing to the other members of the tetrad, 2,4-dimethylpyrimidine 12 and 2,6-dimethylpyrazine 5 also photoisomerize to 3,6-dimethylpyridazine 15. Irradiation of the vapor of pure pyridazine $\mathbf{1 5}$ gave the four members of the tetrad.

The vapor phase photochemistry of these dimethyldiazines thus resembles that of the dimethylpyridines. ${ }^{6}$ In the latter case, the six isomers consisted of two photochemical triads. Although leakage between the two triads was observed, in the present study, no interconversion between the triad and the tetrad was detected.

As shown in Schemes 1 and 2, the observed reactions include pyrazine to pyrimidine, pyrimidine to pyrazine, pyrimidine to pyrimidine, and one example each of a pyrimidine or a pyrazine to a pyridazine phototransposition. To the best of our knowledge, these latter two types of reactions have not been previously reported.

Diazabenzvalene valence isomers were suggested as intermediates in the photoisomerizations of dimethylpyrazines to dimethylpyrimidines. ${ }^{1-3}$ Although such an intermediate can account for pyrazine to 
pyrimidine interconversions, a benzvalene-type species could not account for pyrazine to pyrimidine or pyrimidine to pyrazine interconversions.

The simplest mechanistic scheme for the triad to account for these observations is illustrated in Scheme 3. Photochemical excitation is suggested to lead to intramolecular $\mathrm{C} 2-\mathrm{C} 6$ or $\mathrm{C} 3-\mathrm{C} 5$ bond formation in the case of a pyrazine, or to $\mathrm{C} 2-\mathrm{C} 4$ or $\mathrm{C} 2-\mathrm{C} 6$ bonding in the case of a pyrimidine, leading to the formation of diazaprefulvene intermediates BC-4, BC-9 or BC-10. Interconversion of these bicyclic intermediates via one 1,3-N shift for a pyrazine to pyrimidine interconversion, i.e. $\mathbf{4} \rightarrow \mathrm{BC}-\mathbf{4} \rightarrow \mathrm{BC}-\mathbf{1 0} \rightarrow \mathbf{1 0}$ or $\mathbf{4} \rightarrow \mathrm{BC}-\mathbf{4} \rightarrow \mathrm{BC}-\mathbf{9} \rightarrow \mathbf{9}$ led to the conversion of $\mathbf{4}$ to $\mathbf{1 0}$ or $\mathbf{9}$, respectively. The observed greater yield of $\mathbf{9}$ in this reaction reflects the greater stability of $\mathrm{BC}-\mathbf{9}$ relative to $\mathrm{BC}-\mathbf{1 0}$.

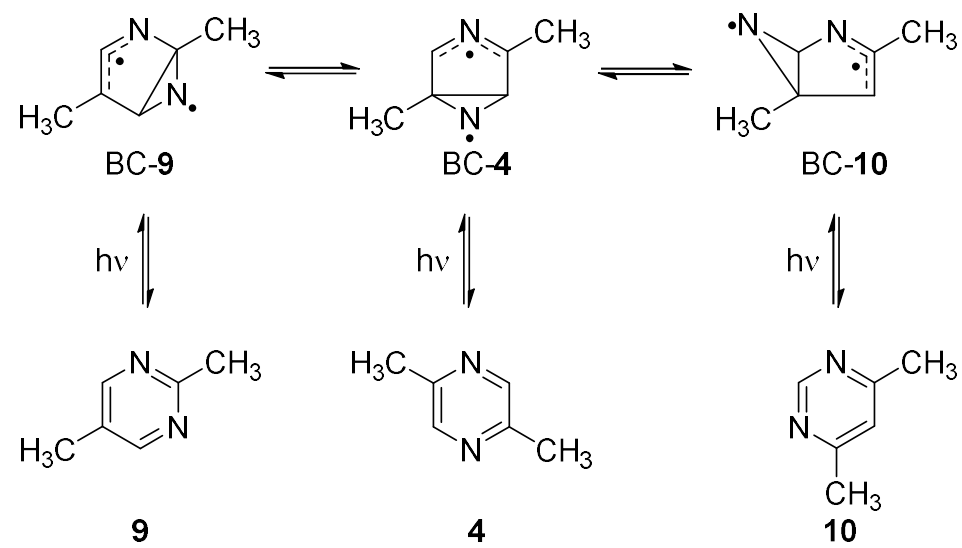

Scheme 3. Mechanism for triad isomerization.

Irradiation of pyrimidines $\mathbf{9}$ or $\mathbf{1 0}$ led to their conversion into pyrazine $\mathbf{4}$ via one 1,3-N migration as in $\mathbf{9} \rightarrow$ BC-9 $\rightarrow$ BC-4 $\rightarrow \mathbf{4}$ or $\mathbf{1 0} \rightarrow$ BC-10 $\rightarrow$ BC-4 $\rightarrow \mathbf{4}$ or into pyrimidines 9 or $\mathbf{1 0}$ via two nitrogen shifts as in $\mathbf{9} \rightarrow$ BC-9 $\rightarrow$ BC-4 $\rightarrow$ BC-10 $\rightarrow \mathbf{1 0}$. The greater yield of pyrazine 4 relative to pyrimidine 10 on irradiation of pyrimidine 9 indicated that the rate of rearomatization of $B C-4 \rightarrow 4$ was faster than the rate of isomerization of $B C-4$ to $B C-$ 10. The slow isomerization of BC-4 to BC-10 reflects the greater stability of BC-4 relative to BC-10. The observed equal yields of diazines 4 and 9 on irradiation of pyrimidine 10 suggests that the rate of isomerization of BC-4 $\rightarrow$ BC-9 was more competitive with the rate of rearomatization of BC-4 to 4 than the rate of isomerization of $B C-4$ to $B C-10$ was with the rearomatization of BC-4 $\rightarrow 4$. Tentatively, this may be because BC-9 was more stable than BC-10 due to their substitution patterns. Thus, interconversion of BC-9, BC-4, and BC-10 followed by rearomatization allowed interconversion of the three members of the triad, but not to any other dimethylpyrazine or dimethylpyrimidine. Furthermore, the relative stabilities of the three bicyclic isomers account for the relative yields of photoproducts.

Irradiation of 4,5-dimethylpyrimidine 11, a member of the tetrad, to low reactant conversion, gave 3,4dimethylpyrimidine 12, 2,3-dimethylpyrazine 14, and 2,6-dimethylpyrazine 5, the other members of the tetrad as primary products. The formation of these products was confirmed by ${ }^{1} \mathrm{H}$ NMR and GLC. More prolonged irradiation of pyrimidine $\mathbf{1 1}$ led to greater quantities of these primary products and to 3,6-dimethylpyridazine 15, which appears to be a secondary photoproduct, presumably formed by photoisomerization of 2,4dimethylpyrimidine 12. Indeed, irradiation of pure pyrimidine 12 gave diazines $\mathbf{1 4}$, 5, and $\mathbf{1 1}$, the other members of the tetrad, and to pyridazine $\mathbf{1 5}$

As shown in Scheme 4, photochemical excitation of pyrimidine $\mathbf{1 1}$ led to C2-C4 or C2-C6 bonding to afford bicyclic intermediates $\mathrm{BC}-\mathbf{1 1}^{\prime}$ and $\mathrm{BC}-\mathbf{1 1}$, respectively. Although both bicyclics are stabilized by methyl 
substitution at the end of the allyl system, BC-11 is expected to be less stable due to methyl substitution at the bridgehead position. This suggests that the yields of products resulting from initial C2-C4 bonding, i.e. diazines 12 and 14, should predominate over product 5 that arises from initial C2-C6 bonding followed by the one $\mathrm{N}$ migration pathway, BC-11' $\rightarrow$ BC-5 $\rightarrow \mathbf{5}$. Although all the product yields in this reaction are low, the observed yields (Figure 4) are consistent with this suggestion. Scheme 4 shows, however, that the two N-migration pathway (11 $\rightarrow$ BC-11' $\rightarrow$ BC-5 $\rightarrow$ BC-11" $\rightarrow$ 11') leads back to the reactant. To the extent that this energy wasting pathway operates, the importance of $\mathrm{C} 2-\mathrm{C} 6$ bonding would be underestimated.

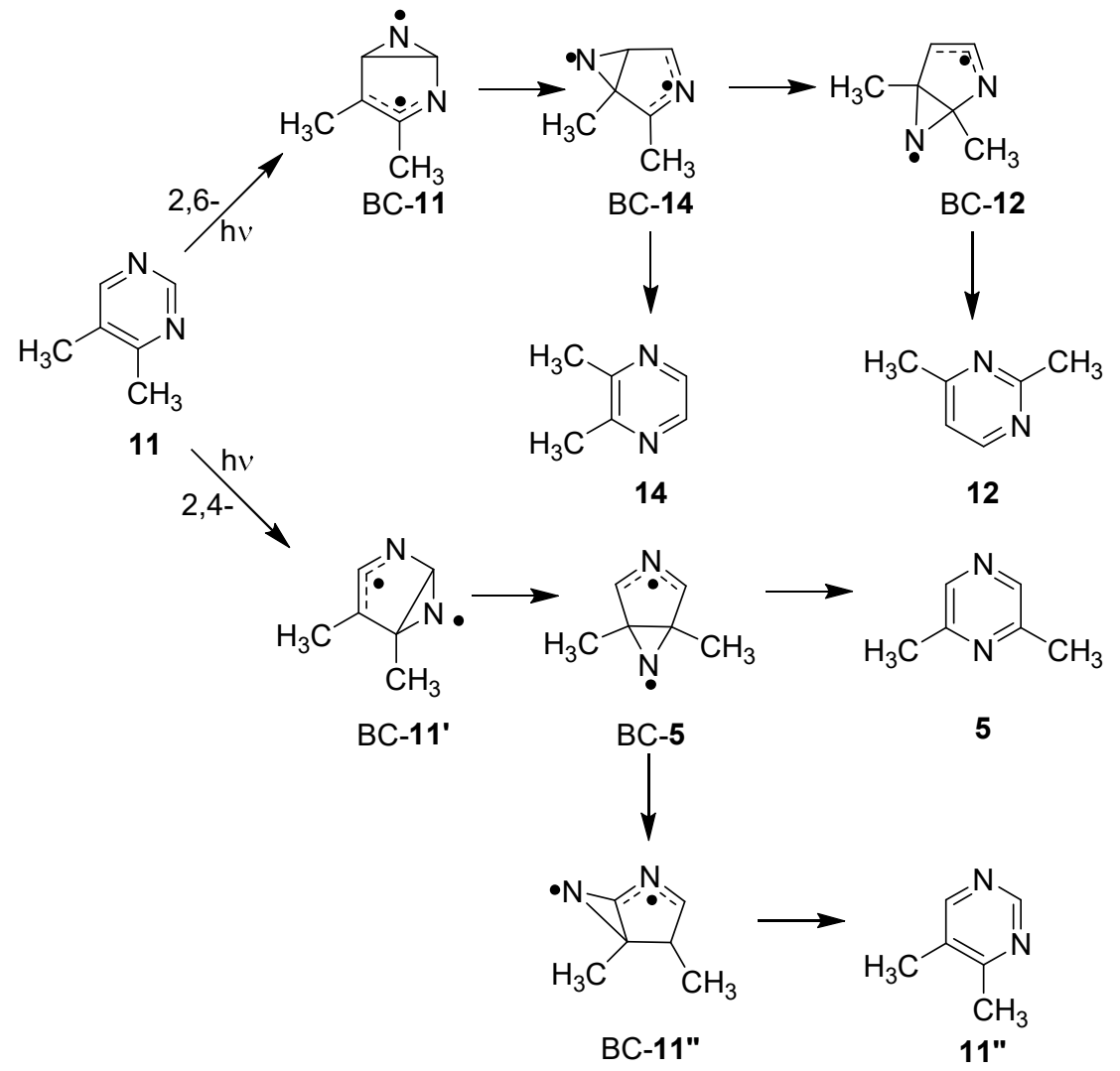

Scheme 4. Photoconversions of 4,5-dimethylpyrimidine 11.

As shown in Scheme 5, irradiation of 2,4-dimethylpyrimidine 12 led to the formation of the other three members of the tetrad, 5, 14, and 11, and also to dimethylpyridazine 15. According to Scheme 5 the two former products, 14 and 11, are formed by initial $\mathrm{C2}-\mathrm{C} 4$ bonding leading to $\mathrm{BC}-12 \mathrm{~B}$ followed by the one $\mathrm{N}$-migration pathway BC-12A $\rightarrow$ BC-14 $\rightarrow 14$ or the two N-migration pathway BC-12A $\rightarrow$ BC-14 $\rightarrow$ BC-11 $\rightarrow \mathbf{1 1}$. Accordingly, the yields of $\mathbf{1 4}$ and $\mathbf{1 1}$ depends on the relative rates of the reactions BC-14 $\rightarrow \mathbf{1 4}$ and BC-14 $\rightarrow B C-\mathbf{1 1}$. Since 11 was observed in greater yield, the isomerization BC-14 $\rightarrow$ BC-11 must be faster than the rearomatization BC-14 $\rightarrow 14$. This may be due to the greater stability of BC-11 relative to BC-14.

Alternatively, $\mathrm{C} 2-\mathrm{C} 6$ bonding in the excited state of dimethylpyrimidine 12 leading to $\mathrm{BC}-12 \mathrm{~A}$ is suggested to yield pyrazine 5 via the pathway $\mathrm{BC}-\mathbf{1 2 B} \rightarrow \mathrm{BC}-\mathbf{5} \rightarrow \mathbf{5}$ or $\mathbf{1 5}$ via the pathway $\mathrm{BC}-\mathbf{1 2 B} \rightarrow \mathrm{BC}-\mathbf{1 5} \rightarrow \mathbf{1 5}$, both involving one $\mathrm{N}$-migration. Since diazines 5 and $\mathbf{1 5}$ were observed in equal yields, the rates of $\mathrm{BC}-\mathbf{1 2 B} \rightarrow \mathrm{BC}-\mathbf{5}$ and $\mathrm{BC}-12 \mathrm{~B} \rightarrow \mathrm{BC}-15$ would have to be equal. It is not clear why pyridazine formation is so significant in this reaction. 


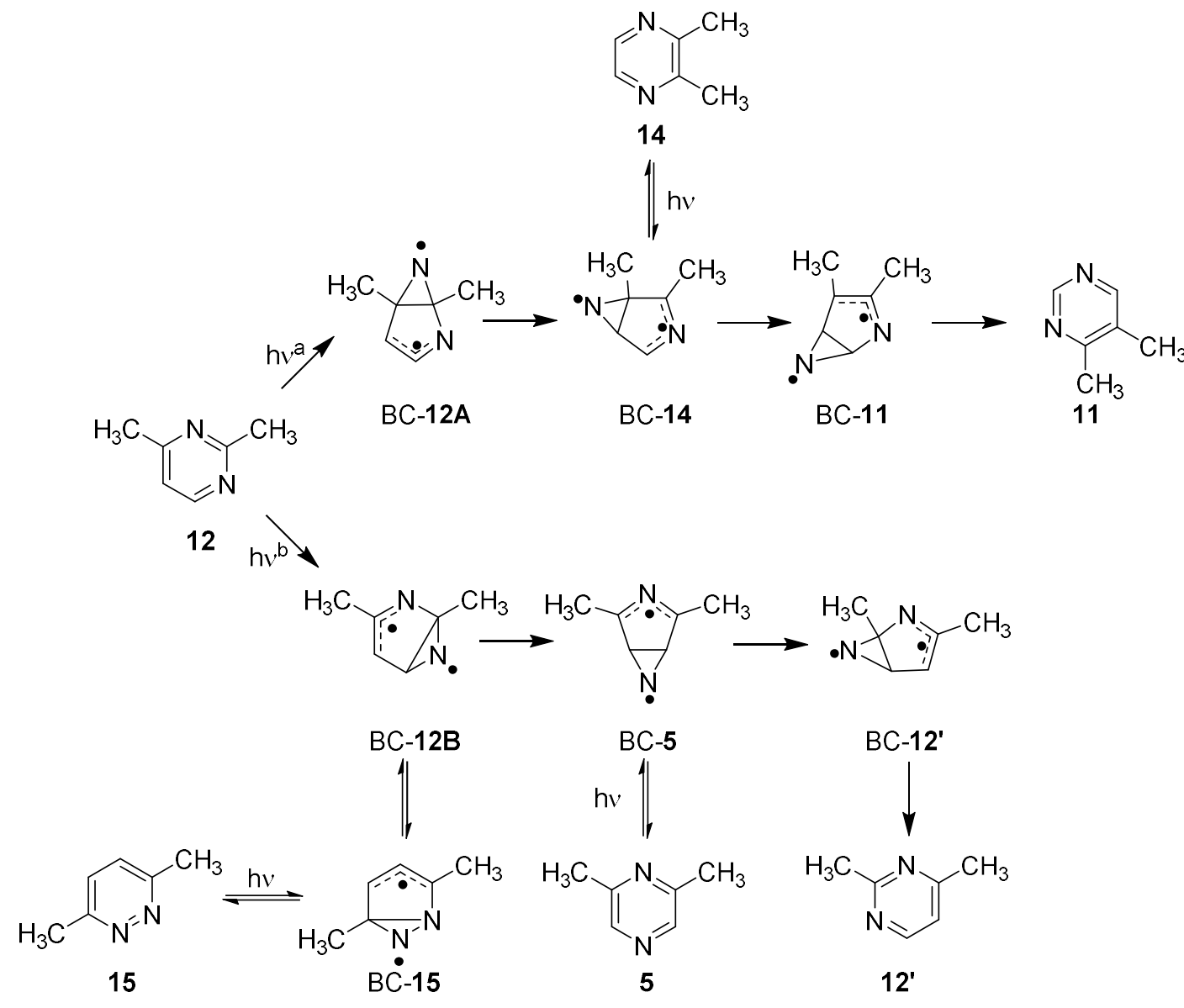

a: 2,4-bonding. b: 2,6-bonding

Scheme 5. Photoconversions of 2,4-dimethylpyrimidine 12.

Scheme 5 also shows that in addition to rearomatization, BC-5, formed from pyrazine $\mathbf{5}$, could isomerize to BC-12' which could rearomatize to pyrimidine 12'. The overall pathway thus leads back to the reactant with the transposition of carbon atoms 2 and 4 and carbon atoms 5 and 6 . To test this possibility, 2,4-dimethylpyrimidine6- $d$ 12-6- $d$ was synthesized and its vapor phase photochemistry examined. Before irradiation the ${ }^{1} \mathrm{H} N M R$ spectrum of pyrimidine 12-6- $d$ from $\delta 6.5$ to 9.0 ppm showed a sharp singlet at $\delta 6.95$ due to the C-5 proton and a very small doublet $(\mathrm{J} 5.1 \mathrm{~Hz})$ at $\delta 8.45$ due to a small amount of residual protons at ring position $6 .{ }^{1} \mathrm{H}$ NMR analysis after irradiation revealed that irradiation was accompanied by the formation of a singlet growing in at the center of the doublet at $\delta 8.45$. As shown in Scheme 6 , this indicates that an isomer of pyrimidine 12-6-d has formed which now has a proton at $\mathrm{C} 6$ and deuterium at $\mathrm{C} 5$. This shows that 2,4-dimethylpyrimidine-6- $d$ (126- $d$ ) has phototransposed to 2,4-dimethylpyrimidine-5- $d(\mathbf{1 2 - 5 - d})$ as demanded by the mechanism in Scheme 5.<smiles>[R6]c1nc(C)nc(C)c1[18OH]</smiles>

Scheme 6. Deuterium scrambling in 2,4-dimethylpyrimidine-6-d (12-6d). 
${ }^{1} \mathrm{H}$ NMR analysis also revealed that pyrimidine 12-6- $d$ phototransposed to diazines $14-6-d, 5-3-d, 11-2-d$ and 12-5-d (Scheme 7).<smiles>[2H]c1cc(C)nc(C)n1</smiles>

$12-6-d$

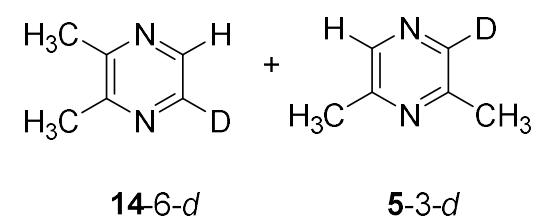<smiles>[2H]c1cnc(C)c(C)n1</smiles>

$11-2-d$<smiles>[2H]c1nc(C)nc(C)c1[2H]</smiles>

$12-5-d$

Scheme 7. Phototranspositions of 2,4-dimethylpyrimidine-6- $d$ (12-6-d).

In a diazaprefulvene intermediate of type $\mathbf{A}$ in Scheme 8, the migrating nitrogen can shift away from the ring nitrogen to yield $\mathbf{B}$, a precursor of a pyrazine, or toward the ring nitrogen to yield $\mathbf{C}$, a precursor of a pyridazine. Tentatively, the general absence of pyridazine products in these reactions can be attributed to a much faster $\mathbf{A} \rightarrow \mathbf{B}$ than $\mathbf{A} \rightarrow \mathbf{C}$ isomerization; the latter $\mathrm{N}$-shift requires trading a strong $\mathrm{N}-\mathrm{C}$ bond for a comparatively weak N-N bond.

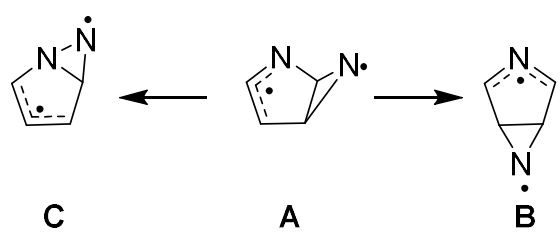

Scheme 8. Isomerization pathways.

In addition of C3-C5 bonding to yield BC-5, 2,6-dimethylpyrazine 5 can undergo C2-C6 bonding to yield BC$\mathbf{5 A}$, a precursor of 4,5-dimethylpyrimidine $\mathbf{1 1}$ via the one $\mathrm{N}$-walk mechanism $\mathbf{5} \rightarrow \mathrm{BC}-\mathbf{5 A} \rightarrow \mathrm{BC}-\mathbf{1 1 A} \rightarrow \mathbf{1 1}$. Since BC-5 (Scheme 5) is more stable than BC-5A, product $\mathbf{5}$ is favored over $\mathbf{1 1 .}$

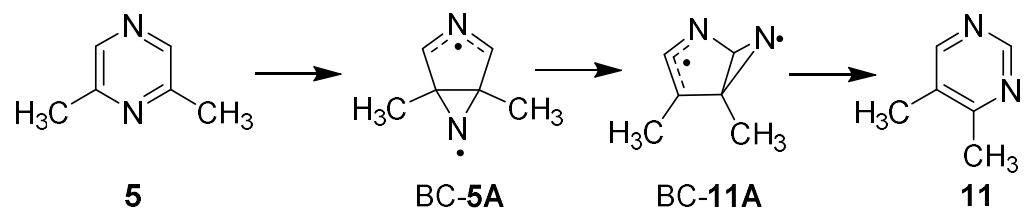

Scheme 9. Phototransposition of 2,6-dimethylpyrazine 5.

As shown in Scheme 5, irradiation of 2,3-dimethylpyrazine 14, would yield only BC-14, which can isomerize to $\mathrm{BC}-\mathbf{1 2 A}$, the precursor of pyrimidine $\mathbf{1 2}$, or $\mathrm{BC}-\mathbf{1 1}$, the precursor of pyrimidine $\mathbf{1 1}$. Based on the relative stability of BC-12A and BC-11, 11 is expected to be the major product. As can be seen in Figure 4, however, 2,4dimethylpyrimidne $\mathbf{1 2}$ is formed in higher yield.

The $0 \rightarrow 0$ bands for $S_{1}$ and $S_{2}$ absorption in pyrazine and pyrimidine vapor occur at 325 and $270 \mathrm{~nm}$ and at 321 and $249 \mathrm{~nm}$, respectively. These absorptions correspond to $S_{1}\left(n, \pi^{*}\right)$ and $S_{2}\left(\pi, \pi^{*}\right)$ states at 88 and $106 \mathrm{kcal}$ 
$\mathrm{mol}^{-1}$ for pyrazine and at 89 and $115 \mathrm{kcal} \mathrm{mol}^{-1}$ for pyrimidine. Methyl substitution in both pyrazine and pyrimidine significantly lowers the $S_{2}$ energy levels, while the $S_{1}$ levels are nearly unchanged. ${ }^{7,8}$ The energies of the $S_{1}\left(n, \pi^{*}\right)$ and $S_{2}\left(\pi, \pi^{*}\right)$ states in 2,3-dimethylpyrazine, for example, lie at 89 and $102 \mathrm{kcal} \mathrm{mol}^{-1}$ while these states in 2,4-dimethylpyrimidine 12 lie at 89 and $109 \mathrm{kcal} \mathrm{mol}^{-1}$. These energies correspond to $\mathrm{S}_{0} \rightarrow \mathrm{S}_{2}\left(\pi, \pi^{*}\right)$ onsets in these UV absorption spectra at $278 \mathrm{~nm}$ and $260 \mathrm{~nm}$, respectively. The $S_{1}\left(n, \pi^{*}\right)$ and $S_{2}\left(\pi, \pi^{*}\right)$ energy levels of other dimethylpyrazines and dimethylpyrimidines are expected to lie at similar energies. Photochemical excitation of these dimethylpyrazines and dimethylpyrimidines with light of $254 \mathrm{~nm}$ is expected to result in the population of $S_{2}\left(\pi, \pi^{*}\right)$ excited states with excess vibrational energy.

The non-radiative decay properties for aza- and diaza-aromatic compounds are similar to those of benzene. ${ }^{9}$ Thus, for these heteroarenes, particularly fast non-radiative decay channels have been observed and it has been suggested that these non-radiation channels may be similar to "channel three" in benzene. ${ }^{10-15}$ In benzene, this decay pathway, which originates in a vibrationally excited $\pi, \pi^{*}$ state, results in the formation of the ground state diradical perfulvene, ${ }^{16}$ the presumed precursor of benzvalene.

For pyridine, theoretical calculations predict that the $S_{2}\left(\pi, \pi^{*}\right)$ state crosses both the $S_{1}\left(n, \pi^{*}\right)$ and $S_{0}$ states along a concerted pathway leading to the ground-state azaprefulvene diradical, ${ }^{17}$ a species which has been suggested to be the key intermediate in the phototransposition reactions of variously substituted pyridines. Furthermore, femtosecond transient absorption spectroscopy has shown that in the condensed phase the $\mathrm{S}_{2}$ $\left(\pi, \pi^{*}\right)$ state of pyridine passes through a conical intersection to the ground-state of the azaprefulvene diradical. ${ }^{18}$ This species reverts to pyridine in greater than $2 \mathrm{~ns} .{ }^{18}$ Considering the observed phototransposition reactions of deuterium, ${ }^{19}$ methyl, ${ }^{6}$ and cyano ${ }^{20}$ substituted pyridines, migration of the $\mathrm{N}$ atom around the cyclopentenyl ring during the lifetime of the azaprefulvene diradical must be possible.

Theoretical calculations also predict that the $S_{2}\left(\pi, \pi^{*}\right)$ state of pyrazine crosses both the $S_{1}\left(n, \pi^{*}\right)$ and $S_{0}$ state along a concerted pathway, leading through a conical intersection to the ground-state diazaprefulvene diradical, ${ }^{21}$ the suggested intermediate in these phototransposition reactions.

Su has used theoretical calculations to study this mechanistic possibility in dimethylpyrazine. ${ }^{22}$ According to his study the Franck-Condon state of 2,6-dimethylpyrazine 5, for example, follows two pathways, leading to conical intersections resulting in the formation of 4,5-dimethylpyrimidine $\mathbf{1 1}$ and 2,4-dimethylpyrimidine 12, respectively. Based on the relative stabilities of the two conical intersections, Su predicts that 4,5dimethylpyrimidine 11 should be the major product whereas 2,4-dimethylpyrimidine should be the minor product. Su states that this is consistent with the product distribution given by Lahami and Ivanoff. ${ }^{1-3}$ To the best of our knowledge, these authors did not give the relative yields of these two products or even identify pyrimidine 12 as a product.

The structure proposed by Su for the conical intersection leading to 4,5-dimethylpyrimidine 11 shows C2 and $\mathrm{C} 6$ moving closer together while the $\mathrm{N}$ moves out of the plane of the remaining 5 -membered ring. The structure resembles the higher energy bicyclic diradical species 5A resulting from C2-C6 bonding of pyrazine 5 suggested earlier. The conical intersection leading to 2,4-dimethylpyrimidine 12, however, appears to be essentially planar with only a small amount of C3-C5 interaction. This suggests that the conical intersection is reached earlier on the reaction coordinate leading to the $\mathrm{C} 3-\mathrm{C} 5$ bonded diradical BC-5. The conical intersection then resembles the Franck-Condon species and is therefore of higher energy then the analogous conical intersection leading to 4,5-dimethylpyrimidine 11.

The results predicted by the theoretical calculations do not agree with our experimental observations. Thus, we observe that pyrimidine $\mathbf{1 2}$ is the major product formed in $\mathbf{1 7 \%}$ yield, whereas pyrimidine $\mathbf{1 1}$ is the minor product formed in $8 \%$ yield. These results agree with the relative stabilities of the precursor bicyclic diradicals. Apparently, more research is required to determine the structures of the species in the conical intersection. ${ }^{23}$ 
Based on their phototransposition chemistry the three dimethylpyrazines and four dimethylpyrimidines can be arranged into two sets: The first, a triad, consisting of the photointerconverting group of 2,5-dimethylpyrazine, 2,5-dimethylpyrimidine, and 4,6-dimethylpyrimidine. Irradiation of any one member of the triad in the vapor phase results in the formation of the other two members. The second, a tetrad, is made up of the four isomers, 2,6-dimethylpyrazine, 2,3-dimethylpyrazine, 2,4-dimethylpyrimidine, and 4,5-dimethylpyrimidine. Irradiation of any one member in the vapor phase results in the formation of the other three. In addition, 2,4dimethylpyrimidine and 2,6-dimethylpyrazine also photoisomerize to 3,6-dimethylpyridazine. Irradiation of the latter in the vapor state afforded the four members of the tetrad. This is the first report of phototransposition of pyrimidine or a pyrazine to pyridazine. Evidence supporting the proposed mechanism was provided with deuterium labeling studies.

These experimental data thus provide a complete mechanistic scheme for the vapor phase phototransposition chemistry of dimethylpyrazines and dimethylpyrimidines.

\section{Experimental Section}

General. ${ }^{1} \mathrm{H}$ and ${ }^{13} \mathrm{C}$ NMR spectra were recorded at 400.1 and $100.6 \mathrm{MHz}$, respectively, in deuteriochloroform on a Bruker FT-NMR system. ${ }^{1} \mathrm{H}$ and ${ }^{13} \mathrm{C}$ NMR chemical shifts were measured relative to internal tetramethylsilane or chloroform, respectively. All ${ }^{13} \mathrm{C}$ NMR spectra are proton decoupled. Mass spectra were recorded with an HP-5970 mass selective detector interfaced to a HP-5880 capillary column gas chromatograph. GLC analysis were performed on a PE-9000 FID instrument equipped with a $15 \mathrm{~m} \times 3 \mathrm{~mm}$ Carbowax bonded capillary column.

The three dimethylpyrazines and 4,6-dimethylpyrimidine were commercially available. 2,4- and 2,5Dimethylpyrimidine, ${ }^{24}$ 4,5-dimethylpyrimidine, ${ }^{25}$ 4,6-dimethylpyrimidine, ${ }^{26,27}$ 3,6-dimethylpyridazine ${ }^{28}$ were synthesized according to literature procedures.

2,4-Dimethylpyrimidine-6- $\boldsymbol{d}(\mathbf{1 2 - 6}-\boldsymbol{d})$. To a suspension of 6-chloro-2,4-dimethylpyrimidine ${ }^{24}(0.40 \mathrm{~g}, 2.8 \mathrm{mmol})$, sodium carbonate $(1.50 \mathrm{~g}), 10 \% \mathrm{Pd}-\mathrm{C}(0.30 \mathrm{~g})$ in methanol-d $(20 \mathrm{~mL})$ was passed $\mathrm{D}_{2}(\mathrm{~g})$ for 4 hours. Kugelrohr distillation $\left(100{ }^{\circ} \mathrm{C}, 1 \mathrm{mmHg}\right)$ gave the title compound $12-6-d$ as a colorless liquid $(0.27 \mathrm{~g}, 87 \%) ;{ }^{1} \mathrm{H} \mathrm{NMR}\left(\mathrm{CDCl}_{3}\right)$ $\delta 2.50(\mathrm{~s}, 3 \mathrm{H}), 2.60(\mathrm{~s}, 3 \mathrm{H}) 7.40(\mathrm{~s}, 1 \mathrm{H}), 8.40$ (residual proton at C-6 (d, J $\left.5.1 \mathrm{~Hz}) ;{ }^{13} \mathrm{C} \mathrm{NMR}_{(\mathrm{CDCl}}\right) \delta 24.1\left(\mathrm{CH}_{3}\right)$, $24.7\left(\mathrm{CH}_{3}\right), 118.0$ (C-5), 156.9 (C-6, t, J $26.8 \mathrm{~Hz}$ ), 167.3 (C-4), 168.2 (C-2).

Irradiation procedure. The dimethylpyrazine or dimethylpyrimidine was placed in a Pyrex tube, attached to the vacuum line, and subjected to three freeze-thaw cycles. The remaining material was then allowed to vaporize into a quartz reaction flask $(3 \mathrm{~L})$ that had been evacuated overnight. The resulting pressure in the reaction flask ranged from 1.0 to 1.5 Torr. The flask was irradiated for $5 \mathrm{~min}$. in a Rayonet reaction equipped with either 2, 4, 6, 8, or 10 low-pressure $2537 \AA$ Hg lamps.

The following Table summarizes the amounts of initial reactant and of final products. 
Table 1. Mass of reactants and recovered products

\begin{tabular}{ccc}
\hline Reactant & Mass of reactant $(\mathrm{mg})$ & Mass of products $(\mathrm{mg})$ \\
\hline 2,3-dimethylpyrazine 14 & 30 & 16 \\
2,6-dimethylpyrazine $\mathbf{5}$ & 32 & 20 \\
2,5-dimethylpyrazine $\mathbf{4}$ & 25 & 12 \\
2,4-dimethylpyrimidine $\mathbf{1 2}$ & 30 & 26 \\
4,5-dimethylpyrimidine 11 & 22 & 12 \\
2,5-dimethylpyrimidine $\mathbf{9}$ & 22 & 12 \\
4,6-dimethylpyrimidine 10 & 26 & 12 \\
\hline
\end{tabular}

Analysis procedure. After irradiation by the above procedure, the $3 \mathrm{~L}$ reaction flask was attached to the vacuum line, and the volatile contents were recovered by pumping it out through a trap cooled in an acetone/dry ice bath. The contents of the trap were weighed (Table 1) and dissolved in diethyl ether or deuteriochloroform for GLC or ${ }^{1} \mathrm{H}$ NMR analysis, respectively. Products were identified by comparison of the observed GLC retention times for the observed chemical shifts with the known retention times or chemical shifts determined in this laboratory.

\section{References}

1. Lahmani, F.; Ivanhoff, N.; Magat, M. C. R. Acad. Sci. Ser. C, 1966, 263, 1005-1006.

2. Lahmani, F.; Ivanhoff, N. Tetrahedron Lett. 1967, 3913-3917.

https://doi.org/10.1016/S0040-4039(01)89751-3

3. Lahmani, F.; Ivanhoff, N. J. Phys. Chem. 1972, 76, 2245-2248.

https://doi.org/10.1021/j100660a012

4. Pavlik, J. W.; Vongnakorn, T. Tetrahedron Lett. 2007, 48, 7015-7018.

https://doi.org/10.1016/j.tetlet.2007.07.144

5. Bryce-Smith, D.; Longuet-Higgins, H. C. J. Chem. Soc., Chem. Commun. 1966, 593-594.

6. Pavlik, J. W.; Kebede, N.; Thompson, M.; Day, A. C.; Barltrop, J. A. J. Am. Chem. Soc. 1999, 121, 56665673.

https://doi.org/10.1021/ja990773r

7. Kumar, D. B. J. Indian Chem. Soc. 1968, 45, 1075-1078.

8. Yamazaki, I.; Sushida, K.; Baba, H. J. Chem. Phys. 1979, 71, 381-387.

https://doi.org/10.1063/1.438081

9. Yamazaki, I.; Murao, T.; Yamanaka, T.; Yoshihara, K. Farday Disc. Chem. Soc. 1983, 75, 395-405. https://doi.org/10.1039/dc9837500395

10. Riedle, E.; Weber, T.; Shubert, U.; Neusser, H. J.; Schlag, E. W. J. Chem. Phys. 1990, 93, 967-978. https://doi.org/10.1063/1.459123

11. Suzuki, T.; Ito, M. J. Chem. Phys. 1989, 91, 4564-4570.

https://doi.org/10.1063/1.457635

12. Hornberger, H.; Sharp, C. M. Chem. Phys. 1986, 101, 67-79. 
https://doi.org/10.1016/0301-0104(86)87023-9

13. Sobolewski, A. L.; Czermiński, R. Chem. Phys. 1989, 130, 123-128.

https://doi.org/10.1016/0301-0104(89)87041-7

14. Sobolewski, A. L. J. Chem. Phys. 1990, 93, 6433-6439.

15. Sobolewski, A. L.; Lim, E. C.; Siebtant, W. Int. J. Quantum Chem. 1991, 39, 309-324. https://doi.org/10.1002/qua.560390309

16. Palmer, I. J.; Ragazos, I. N.; Bernardi, F.; Olivacci, M.; Robb, M. A. J. Am. Chem. Soc. 1993, 115, 673-682. https://doi.org/10.1021/ja00055a042

17. Sobolewski, A. L.; Domcke, W. Chem. Phys. Lett. 1991, 180, 381-386. https://doi.org/10.1016/0009-2614(91)90337-9

18. Chachisvillis, M.; Zewail, A. H. J. Phys. Chem. A 1999, 103, 7408-7418. https://doi.org/10.1021/jp991821x

19. Pavlik, J. W.; Laohhasurayotin, S. J. Org. Chem. 2008, 73, 2746-2752. https://doi.org/10.1021/jo7026799

20. Pavlik, J. W.; Laohhasurayotin, S.; Vongnakorn, T. J. Org. Chem. 2007, 72, 7116-7124. https://doi.org/10.1021/jo070810u

21. Sobolewski, A. L.; Woywod, C.; Domcke, W. J. Chem. Phys. 1993, 98, 5627-5641. https://doi.org/10.1063/1.464907

22. Su, M.-D. J. Phys. Chem. A, 2006, 110, 9420-9428. https://doi.org/10.1063/1.464907

23. Kebede, N.; Pahel, A.; Pavlik, J. W.; Hoffman, G., Paper No. 193, $215^{\text {th }}$ Meeting of the American Chemical Society, August 21-25, 2016, Philadelphia, PA.

24. Hasapis, X.; Macleod, J. A. Tetrahedron 1979, 35, 2087-2090. https://doi.org/10.1016/S0040-4020(01)88985-7

25. Hull, R.; Lovell, B. J.; Openshaw, H. T.; Payman, L. C.; Todd, A. R. Synthetic Antimalarials. Part III, 1946, 357-362.

26. Hunt, R. R.; McOmie, J. F. W.; Sayer, E. R. J. Chem. Soc. 1959, 525-530. https://doi.org/10.1039/jr9590000525

27. Reznik, V. S.; Muslink, A. A.; Shirshov, A. N. Pharm. Chem. J. 2001, 35, 672-671. https://doi.org/10.1023/A:1015396630902

28. Fariña, F.; Victoria, M. M. Añal. Quim. 1981, 213-216. 